\title{
RESENHA
}

\section{ZIEM, A. Frames of understanding in text and discourse. Amsterdam: John Benjamins, 2014. $441 \mathrm{p}$.}

Esta obra se propõe, como o título indica, a delinear uma abordagem que permita aplicar frames semânticos a análises textuais e discursivas, considerando evidências empíricas provenientes de corpora. O conceito de frame semântico é o cerne da teoria da Semântica de Frames, postulada por Charles Fillmore (1982; 1985), a qual defende que os falantes entendem o significado de uma palavra ou expressão a partir de sua associação a uma cena esquemática mental. A teoria pode ser definida como

[...] o estudo de como, enquanto parte de nosso conhecimento da língua, associamos formas linguísticas (palavras, expressões fixas, padrões gramaticais) a estruturas cognitivas - os frames - que determinam em grande parte o processo (e o resultado) de se interpretar essas formas (FILLMORE; BAKER, 2010, p.314, grifo nosso).

Em seu artigo Frames and the semantics of understanding (FILLMORE, 1985), o pai da Semântica de Frames diferencia abordagens opostas à semântica das condições de verdade, categorizando-as como teorias da semântica da compreensão (U-Semantics) ${ }^{1}$. Conforme o autor, a U-Semantics, que abrange a Semântica de Frames, mostra-se um programa natural para se examinar o significado lexical, visto que se trata de um estudo empírico que permite a análise do significado por meio de situações reais de comunicação. A partir desse viés, a obra de Ziem propõe uma metodologia de análise baseada em frames que vai além da atribuição de papéis semânticos, conforme postula a FrameNet ${ }^{2}$. Para isso, o autor também se apropria de conceitos desenvolvidos por outros linguistas no cenário alemão - dentre eles Konerding (1993), Lönneker (2003) e Fraas (1996).

\footnotetext{
1 No original: "semantics of understanding", em contraposição a "semantics of truth" (FILLMORE, 1985, p. 222).

2 A FrameNet foi o primeiro recurso lexicográfico computacional baseado em frames, cujo objetivo é descrever as propriedades sintáticas e semânticas das palavras na língua inglesa a partir de corpora (ATKINS; FILLMORE; JOHNSON, 2003).
}

A obra é dividida em duas partes principais: a primeira diz respeito à contextualização da Semântica da Compreensão e do conceito de frame, apresentando-se também o paradigma holístico da Linguística Cognitiva, a qual vê a linguagem como uma habilidade dependente dos demais processos cognitivos. $\mathrm{O}$ autor a contrapõe com a visão modularista da mente, que vê a linguagem como um módulo mental que funciona de maneira isolada. A partir disso, Ziem mostra como uma abordagem holística por meio da Semântica da Compreensão é mais adequada para o estudo do significado.

Conforme o autor, os frames de compreensão - no inglês, frames of understanding - podem ser entendidos tanto como estruturas cognitivas que organizam nossa experiência quanto como ferramenta analítica para se identificarem esses frames a partir de evidências textuais e discursivas. Visto que a Semântica da Compreensão evidencia não haver separação entre conhecimento linguístico e conhecimento de mundo, em virtude da visão enciclopédica de significado, Ziem considera que expressões linguísticas estão sempre inseridas em um "espaço de compreensão" estruturado por meio desses frames.

Baseando-se também nas abordagens de Minsky (1974) e de Coulson (2001), Ziem leva em conta três constituintes que embasam a estrutura esquemática dos frames: slots, fillers e valores default. Os slots são realizados linguisticamente por determinadas expressões (fillers); já os valores default são inferidos e mentalmente adicionados a um frame pelos falantes. Por exemplo, em uma frase como a piscina mede 2 metros, temos um slot de medida relativo ao termo piscina, cujo filler é mede dois metros. Contudo, ao assimilar a frase, um falante também ativa diversos valores não explicitados, ou valores default, como os usos que se faz de uma piscina ou o material que possivelmente a constitui.

A ideia de slot também se apoia nos escritos de Fillmore referentes ao frame como uma estrutura que permite ao falante "preencher detalhes", visto que entender uma palavra "requer conhecer o cenário; 
entender uma sentença contendo esse mundo requer conhecer o cenário e usar o conteúdo lexical e a estrutura gramatical do resto da sentença para preencher alguns detalhes [...]". (FILLMORE, 1976, p. 28)3. Quanto a esse preenchimento de detalhes, o autor assinala que os frames não necessariamente trazem todas as minúcias do evento, mas que o processo de compreensão do falante, ao longo da inserção de um frame num ato de comunicação, inclui a busca de informações específicas, ou mesmo o esclarecimento de dúvidas com seu interlocutor, conforme seu interesse ou necessidade. Para Ziem, nesses textos seminais, Fillmore não traz muitas pistas quanto à verificação empírica de slots. Além disso, o autor considera que perspectivas como a FrameNet acabam sendo "sintaticocentristas", no sentido de fazer da estrutura argumental o lugar dos elementos ou slots do frame, o que impede que se considerem facetas do conhecimento enciclopédico que não se instanciam necessariamente na estrutura das frases.

Em vista disso, Ziem apropria-se da abordagem de Lönneker (2003), a qual propõe que frames podem ser identificados por meio de proposições, que se referem, nos termos de Searle (1969), à "dimensão do conteúdo da frase que pertence ao conteúdo proposicional da sentença, independentemente de seu modo de expressão" (ZIEM, 2014, p. 245) ${ }^{4}$. Desse modo, uma proposição diz algo sobre uma entidade em particular - o objeto de referência, sobre o qual se atribui uma predicação. Assim, predicação significa "alocação de predicados a um objeto de referência" (ZIEM, 2014, p. 246). Importa ressaltar que, nesse contexto, a referência não concerne ao mundo objetivo, mas sim ao mundo construído e projetado pelos falantes.

A partir dessas premissas, a segunda parte da obra concerne à proposta de frame do autor, a qual é formulada da seguinte forma: "Um frame evocado corresponde ao conteúdo referencial de uma proposição [...]. Em consonância com isso, slots mostram quais predicações podem potencialmente ocorrer" (ZIEM, 2014, p. 246) . É possível relacionar essa forma de conceituar o frame com a afirmação de Lakoff ([1987] 1990) quanto à função dos frames de capturarem a estrutura proposicional de modelos cognitivos - para ele, o frame seria um Modelo Cognitivo Idealizado proposicional que não inclui

\footnotetext{
3 No original: "Understanding this word requires knowing the whole scenario; understanding a sentence containing this word requires knowing the scenario and using the lexical contents and grammatical structure of the rest of the sentence to fill in some of the details; $[. .$.$] ".$

4 No original: "that dimension of sentence content that pertains to the propositional content of a sentence regardless of its mode of expression." (ZIEM, 2014, p. 245)

5 No original: "An evoked frame corresponds to the referential content of a proposition [...]. Accordingly, slots show which predications can potentially occur."

6 No original: "A linguistic expression refers to a cognitive unit by evoking a frame, which then opens a potential reference area. (ZIEM, 2014, p. 251).
}

projeções imaginativas como metáfora, metonímia, ou imagem mental (LAKOFF, [1987] 1990). Para Ziem (2014), a captura da estrutura proposicional do frame é feita por meio da identificação de seus elementos - em sua abordagem, a identificação de slots, fillers e valores default.

Portanto, nessa perspectiva, a estrutura gestáltica do frame pode ser, em certa medida, traduzida por meio de estruturas proposicionais (LÖNNEKER, 2003 apud ZIEM, 2014) que refletem conhecimento enciclopédico. Mas resta esclarecer: conforme a obra do autor, como se identificam os frames para fins de análise textual? Ziem considera que, se conjuntos de proposições representam frames, identificar seus subcomponentes (referência e predicação) consiste em uma proposta analítica adequada. Dessa forma, partindo das noções de referência e predicação, em um corpus textual, é necessário se identificar o evocador para então se verificar como essa entidade é predicada, ou seja, quais são as suas propriedades, características ou outros atributos recorrentes que aparecem no corpus. Como resultado, obtém-se uma lista de predicações que revelam as facetas de conhecimento do frame em determinado conjunto de textos. O quadro a seguir esquematiza a relação entre proposição, referência/predicação e evocador de framel elementos:

\begin{tabular}{|c|c|}
\hline \multirow{2}{*}{$\begin{array}{c}\text { Evocador do frame } \\
\text { ativado }\end{array}$} & Slot \\
\cline { 2 - 2 } & Filler \\
\hline Referência & Predicação \\
\hline \multicolumn{2}{|c|}{ Proposição } \\
\hline
\end{tabular}

Fonte: Adaptado de Ziem (2014, p. 247)

Figura 1. constituintes estruturais dos frames conforme os conceitos de proposição, referência e predicação

Conforme apontamos anteriormente, é importante frisar que a referência é transposta para a abordagem de Ziem como um ato cognitivo de referenciação em uma área conceptual abarcada pelo frame. Desse modo, "Uma expressão se refere a uma unidade cognitiva ao evocar um frame, o qual então abre uma área de referência potencial" (ZIEM, 2014, p. 251) ${ }^{6}$. O frame, assim, pode ser entendido como área de projeção por meio das quais referenciamos entidades: a partir de um evocador de frame, o falante processa os slots presentes no texto e as informações inferenciais, ou valores default, que seu conhecimento de mundo permite apreender sobre a palavra ou expressão. Além disso, quando se processa um evocador de frame e seus slots associados em um texto ou outra situação 
de comunicação, os próprios fillers podem evocar outros frames.

Ziem parte da premissa de que a identificação de frames, considerando facetas de conhecimento enciclopédico, implicam uma análise desengajada de estruturas sintáticas. Em vez de ter como base a estrutura argumental para identificação de evocadores e de elementos de frame, o autor utiliza o termo "pontos de referência" para denominar os slots que caracterizam a estrutura do frame. Quanto mais frequentes são as predicações correspondentes a um slot, mais convencionalizadas e relevantes elas são no que concerne às facetas de conhecimento envolvidas.

Ao longo da explicitação desses conceitos, o autor faz um esclarecimento quanto à questão da predicação: ao se selecionar um evocador em um corpus autêntico, as informações que constituem predicações dificilmente estarão explícitas - Ziem denomina-as como "predicações (quase)explícitas". Dessa forma, ao identificar o evocador de frame, o analista deve explicitar as predicações relacionadas. Na obra, o autor exemplifica a explicitação de predicações relativas ao frame investidor financeiro, a partir da qual trazemos a ilustração a seguir:

\section{- Ações são compradas por investidores financeiros após quedas recentes em Wall Street.}

Tendo o autor o objetivo de fazer um levantamento de predicações relativas ao frame investidor financeiro, foi necessário posicioná-lo na posição de sujeito e reformular a frase para evidenciar a predicação:

\section{- Investidores financeiros compram ações.}

Comprar ações, juntamente com outras funções de investidores que aparecerem no corpus (por exemplo, investidores financiam empresas, investidores gerenciam carreiras e investidores administram carteiras de investimento) são agrupados e constituem-se como fillers de um slot, que pode ser denominado [função profissional]. Esse processo é chamado de "redução de tipo hiperonímico" das predicações (ZIEM, 2014, p. 383).

Obviamente, esse levantamento trará um número elevado de predicações que revelarão facetas de conhecimento bastante específicas do corpus de estudo, e que nem sempre são essenciais à caracterização do frame. Por exemplo, Ziem encontrou a predicação investidores destroem empregos, que pode ser considerada como faceta secundária em comparação com os fillers mencionados anteriormente, visto que não é inerente às atividades profissionais de todos os investidores - consiste mais em uma consequência da ação de alguns deles. No entanto, essa predicação tem uma dimensão importante em termos de faceta do conhecimento ativada pelos falantes, dado que mostra uma perspectiva bastante específica que é parte do frame de compreensão investidor financeiro. Em vista disso, Ziem (2014, p. 361) considera que “[...] predicações explícitas devem ser manualmente e interpretativamente classificadas. Isso deve ser definido caso a caso de forma a cumprir com os critérios específicos e produzir resultados replicáveis e confiáveis"7.

Outra observação importante a respeito de sua obra refere-se ao modo de análise desprendido de estruturas argumentais. Como referimos anteriormente, as próprias predicações já evidenciam outros frames que podem ser analisados. Esse postulado condiz com a frase de Lakoff (2004: 3), quando o autor afirma que toda e qualquer palavra evoca um frame. Assim, na frase mencionada anteriormente (Investidores financeiros compram ações), a análise estava voltada ao frame investidores financeiros, mas outros frames estão envolvidos (por exemplo, ações, compra, compra de ações).

Como propõe a obra de Ziem, a principal vantagem de se optar por uma identificação de slots, para além da estrutura sintática, é a possibilidade de se identificarem predicações mesmo quando não estão atreladas a essas informações, apesar de estarem no texto. Desse modo, a metodologia postulada por Ziem permite que se identifiquem frames a partir de qualquer evocador presente texto. Além disso, observamos que sua proposta é também adequada para relacionar frames a processos conceptuais mais dinâmicos, como espaços mentais (FAUCONNIER, 1994) e mesclagens conceptuais (FAUCONNIER; TURNER, 2002), visto que a teoria permite que se verifiquem os slots dos frames que constituem esses mapeamentos.

Portanto, consideramos que a obra de Ziem proporciona uma metodologia sistemática para exploração de corpora, de modo a se identificarem slots de frames a partir de dados empíricos. Ao reforçar que todas as facetas de conhecimento, expressas por meio de slots, são importantes, essa abordagem permite um trabalho mediado por análise quantitativa e qualitativa dos dados. Finalmente, o livro reforça o fato de que as agendas de pesquisa em Linguística Cognitiva têm primado cada vez mais por uma convergência com estudos do texto e do discurso, visto que esse espaço de compreensão de significados, postulado pelo autor, está ancorado nas interações sociais entre falantes - assim, frames e outros dispositivos conceptuais são constantemente (re)construídos e partilhados.

\section{Aline Nardes dos Santos Rove Luiza de Oliveira Chishman Universidade do Vale do Rio dos Sinos - Unisinos São Leopoldo - Rio Grande do Sul - Brasi}

\footnotetext{
7 No original: "[...] explicit predications must be manually and interpretively classified. These must be decided on a case-by-case basis to be able to fulfil the specified criteria and produce replicable and reliable results." (ZIEM, 2014, p. 361).
} 


\section{Referências}

ATKINS, S.; FILLMORE, C.J.; JOHNSON, C.R. Lexicographic Relevance: Selecting Information from Corpus Evidence. International Journal of Lexicography, Oxford, v. 16, n. 3, p. 251-281, 2003. Disponível em: <ijl.oxfordjournals. org/content/16/3/251.full.pdf>. Acesso em: 20 set. 2015.

COULSON, S. Semantic leaps. Frame-shifting and conceptual blending in meaning construction. New York: Cambridge University Press, 2001.

FAUCONNIER, G. Mental spaces. Cambrigde: Cambridge University Press, 1994.

FAUCONNIER, G.; TURNER, M. The Way We Think: conceptual blending and the mind's hidden complexities. New York: Basic Books, 2002.

FILLMORE, C. J. Frame semantics and the nature of language. In: Annals of the New York Academy of Sciences: Conference on the Origin and Development of Language and Speech. New York, 1976a. Vol. 280, p. 20-32.

FILLMORE, C. J. Frame Semantics. In: Linguistics in the Morning Calm. Seoul: Hansinh Publishing, 1982.

FILLMORE, C. J. Frames and the semantics of understanding. In: Quaderni di Semantica, v. 6, n. 2, p. 222-254, 1985.

FILLMORE, C. J.; BAKER, C. A frames approach to semantic analysis. In: HEINE, B.; NARROG, H. (Eds.). The Oxford Handbook of Linguistic Analysis. New York: Oxford University Press, 2010. p. 313-339.
FRAAS, C. Gebrauchswandel und Bedeutungsvarianz in Textnetzen. Die Konzepte "Identität" und "Deutsche" im Diskurs zur deutschen Einheit. Tübingen: Narr, 1996.

KONERDING, K.-P. Frames und lexikalisches Bedeutungswissen. Untersuchungen zur linguistischen Grundlegung einer Frametheorie und zu ihrer Anwendung in der Lexikographie. Tübingen: Niemeyer, 1993.

LAKOFF, G. Women, fire and dangerous things. What categories reveal about mind. Chicago: University of Chicago Press, 1990.

LAKOFF, G. Don't think of an elephant! Know your values and frame the debate. Vermont: Chelsea Green Publishing, 2004.

LÖNNEKER, B. Konzeptframes und Relationen. Extraktion, Annotation und Analyse französischer Corpora aus dem World Wide Web. Berlin: Aka, 2003.

MINSKY, M. A framework for representing knowledge. In: Artificial Intelligence Memo, n. 306. Cambridge, MA: Massachusetts Institute of Technology, 1974.

RUPPENHOFER, J. et al. FrameNet II: extended theory and practice. Berkeley, California: International Computer Science Institute, 2010. Disponível em: $<$ https://framenet2.icsi.berkeley. edu/docs/r1.5/book.pdf>. Acesso em: 20 ago. 2013.

SEARLE, J. R. Speech acts: an essay in the philosophy of language. Cambridge: Cambridge University Press, 1969.

Recebido: 03 de fevereiro de 2016. Aprovado: 02 de junho de 2016.

Contato: aline.nardes@gmail.com rove@unisinos.br 